\title{
ENERGIA SOLAR ATRAVÉS DO SISTEMA FOTOVOLTAICO: REDUÇÃO DE GASTOS, GERAÇÃO DE ENERGIA E PRESERVAÇÃO DO MEIO AMBIENTE
}

\author{
Cassio M. Hasegawa (CENTRO UNIVERSITÁRIO CAMPO REAL) adm-
} cassiohasegawa@camporeal.edu.br

Gabriel Pietrobon (CENTRO UNIVERSITÁRIO CAMPO REAL) admgabrielpietrobon@camporeal.edu.br Jeverson Ketzer (CENTRO UNIVERSITÁRIO CAMPO REAL) admjeversonketzer@camporeal.edu.br

Mônica Cristina Antoniucci de Lima Motta (CENTRO UNIVERSITÁRIO CAMPO REAL) prof_monicamotta@camporeal.edu.br

\section{Resumo}

A presente pesquisa tem como objetivo expor os benefícios da aquisição do sistema de energia solar fotovoltaico na indústria madeireira. Através de uma empresa especializada em energia solar, é instalado painéis solares onde captam a luz do sol e transformam em energia. Este método é super amigável ao meio ambiente sendo considerado como uma fonte de energia renovável. O sistema fotovoltaico resulta em uma redução considerável no gasto com energia elétrica à concessionárias, de acordo com a ANEEL (Agência Nacional de Energia Elétrica) caso a empresa venha a gerar mais energia do que o consumido, o mesmo se torna um crédito para o mês seguinte. Conclui-se que a geração de energia através do sistema fotovoltaico traz benefícios tanto para a natureza quanto para a empresa, pois o setor madeireiro pode contar com esse método eficaz de geração de energia trazendo lucro para si e tendo um retorno de investimento em aproximadamente 3 anos e 7 meses e ao mesmo tempo preservando o meio ambiente mantendo o equilíbrio da fauna e flora.

Palavras-Chaves: Energia Solar. Fotovoltaico. Indústria. Madeireiras. Energia Elétrica

\section{Introdução}

Com o intuito de otimizar os gastos com energia elétrica e contribuir com a sustentabilidade, a energia solar propõe a idéia de energia limpa e renovável pois segundo Villalva (2020) em comparação com os combustíveis fósseis apresentam impactos reduzidos na natureza e não 
originam resíduos ou emissões de poluentes. O autor, porém ressalta que a exploração de qualquer fonte de energia provoca alterações no meio ambiente e pode causar impactos de maior ou menor intensidade.

A energia solar funciona com painéis solares que captam a luz do sol e geram a energia que é transportada até o inversor solar, responsável por transformar a energia elétrica gerada para o formato da rede elétrica. A geração de energia ocorre por meio do efeito fotovoltaico. Sousa (2020) esclarece que o efeito fotovoltaico nada mais é do que a conversão direta da radiação solar em energia elétrica. Composto por painéis, módulos e equipamentos elétricos o sistema fotovoltaico não necessita de grande quantidade de radiação para funcionar, no entanto depende da quantidade de nuvens no céu, pois se houver poucas nuvens, maior será a produção de eletricidade (SOUSA, 2020).

Voltado para a economia e sustentabilidade, a energia pode ser utilizada em vários locais, sendo em residências, agricultura e até mesmo em indústrias. O setor madeireiro atualmente demanda de alto consumo de energia, para Quantum (2019) o alto consumo de energia é devido à quantidade, capacidade e ao tempo de funcionamento diário das máquinas. Ao utilizar o sistema fotovoltaico a empresa/consumidor recebe um crédito da ANEEL (Agência Nacional de Energia Elétrica) em sua fatura pela energia produzida. Segundo a ANEEL (2020) caso a energia inserida na rede seja superior a energia consumida, cria-se um crédito na qual não pode ser revertido em dinheiro, porém pode ser abatido nas unidades consumidoras dos meses seguintes. Sendo assim a energia solar uma ótima opção de economia de energia elétrica para indústrias.

Com a redução no valor de energia elétrica das concessionárias, o sistema fotovoltaico é um grande investimento que pode trazer benefícios para a indústria madeireira e para o meio ambiente, no entanto exige certa disposição financeira para implementá-lo.

O presente artigo tem como objetivo expor uma viabilidade financeira para a indústria madeireira com a implementação do sistema fotovoltaico, mostrando assim a redução do custo de energia elétrica às concessionárias e beneficiando o meio ambiente por meio de uma fonte limpa e renovável.

\section{Sistema Fotovoltaico na Indústria Madeireira: Economia e Sustentabilidade}

Para Müller (2020) a instalação das placas de energia solar é realizada com muita facilidade em indústrias e fábricas, onde a mesma dispõe de uma grande área para a instalação dos 
painéis. Outro benefício seria sobre as questões ambientais, pois de acordo com Solarprime (2019) a iluminação solar é uma fonte natural e inesgotável de energia, justamente por isso que ao investir em energia solar a indústria consegue diminuir o uso dos recursos naturais e esgotáveis presentes no meio ambiente.

Como dito anteriormente, o alto consumo de energia devido a grandes máquinas utilizadas são o motivo principal para requerer uma economia na conta de energia elétrica. "Para empresas do setor madeireiro, a conta de energia elétrica é uma das despesas obrigatórias que mais onera o caixa" (ELYSIA, 2020). Diante da necessidade de economia em energia elétrica, o sistema fotovoltaico se destaca por gerar energia a partir dos raios solares fazendo com que assim seja gerada energia de uma fonte renovável e limpa.

A energia solar gera uma grande economia na conta de luz, o investimento realizado para a aquisição e instalação das placas solares acaba sendo pago pela economia de dinheiro que se tem quando o sistema fotovoltaico começa a funcionar.

Em uma comparação dos setores econômicos, eletricidade e aquecimento seguem líderes em emissão de gases na natureza, de acordo com o site Uol (2015) às emissões dos gases de efeito estufa colocam em risco e causam mudanças climáticas que afetam toda a fauna e flora, como também pode causar seca e chuvas intensas.

Para Sunergia (2018) a redução de emissões de gases de efeito estufa no meio ambiente é um ponto positivo para a aquisição do sistema fotovoltaico, pois como já dito, é uma fonte de energia limpa e renovável.

Existem vários tipos de usinas que geram energia elétrica, porém todas impactam de forma diferente no meio ambiente, a seguir é possível observar as vantagens e desvantagens de cada umas delas. 
Tabela 1 - Vantagens e desvantagens de cada usina geradora de energia

\begin{tabular}{|c|c|c|}
\hline TIPO DE USINA & VANTAGENS & DESVANTAGENS \\
\hline Hidroelétrica & $\begin{array}{l}\text { - Emissão de gases causadores do efeito estufa } \\
\text { muito baixa } \\
\text { - Baixo custo }\end{array}$ & $\begin{array}{l}\text { - Impacto social e ambiental do represamento } \\
\text { do rio } \\
\text { - Dependência (limitada) das condições } \\
\text { climáticas }\end{array}$ \\
\hline $\begin{array}{c}\text { Termoelétrica } \\
\text { a carvão }\end{array}$ & $\begin{array}{l}\text { - Baixo custo de construção e combustível } \\
\text { - Alta produtividade } \\
\text { - Independência das condições climáticas }\end{array}$ & $\begin{array}{l}\text { - Emissão de gases de efeito estufa muito alta (é } \\
\text { a que mais emite) } \\
\text { Poluição local do ar com elementos que } \\
\text { causam chuva ácida e afetam a respiração }\end{array}$ \\
\hline $\begin{array}{l}\text { Termoelétrica } \\
\text { a gás natural }\end{array}$ & $\begin{array}{l}\text { - Baixo custo de construção } \\
\text { - Independência das condições climáticas } \\
\text { - Baixa poluição local (comparada à } \\
\text { termoelétrica a carvão) }\end{array}$ & $\begin{array}{l}\text { - Emissão de gases de efeito estufa alta (menor } \\
\text { que a do carvão, porém significativa) } \\
\text { - Custo de combustível muito oscilante (atrelado } \\
\text { ao petróleo) }\end{array}$ \\
\hline $\begin{array}{l}\text { Termoelétrica } \\
\text { a biomassa }\end{array}$ & $\begin{array}{l}\text { - Baixo custo de construção e combustível } \\
\text { - Emissão de gases de efeito estufa } \\
\text { praticamente se anula (o ciclo do carbono fica } \\
\text { perto de ser fechado) } \\
\text { - Independência das condições climáticas }\end{array}$ & $\begin{array}{l}\text { - Disputa do espaço do solo com a produção de } \\
\text { alimentos } \\
\text { - Caso haja desmatamentos para o cultivo, cria } \\
\text { um novo problema ambiental }\end{array}$ \\
\hline Nuclear & $\begin{array}{l}\text { - Emissão de gases de efeito estufa } \\
\text { praticamente inexistente } \\
\text { - Alta produtividade } \\
\text { - Independência das condições climáticas }\end{array}$ & $\begin{array}{l}\text { - Alto custo (exige investimentos em segurança) } \\
\text { - Produção de rejeitos radioativos } \\
\text { masco de acidentes (a probabilidade é baixa, } \\
\text { masos são gravíssimos) }\end{array}$ \\
\hline Eólica & $\begin{array}{l}\text { - Emissão de gases de efeito estufa } \\
\text { praticamente inexistente } \\
\text { - Impacto ambiental mínimo }\end{array}$ & $\begin{array}{l}\text { - Baixa produtividade } \\
\text { - Dependência das condições climáticas } \\
\text { - Poluição visual }\end{array}$ \\
\hline Fotovoltaica & - Baixo impacto ambiental & $\begin{array}{l}\text { - Alto custo } \\
\text { - Baixa produtividade }\end{array}$ \\
\hline
\end{tabular}

Fonte: G1 São Paulo (2011)

\section{Metodologia}

A metodologia são os estudos utilizados para chegar a um resultado em uma pesquisa, para Deslandes, Gomes e Minayo (2009, p.14) "inclui simultaneamente a teoria da abordagem (método), os instrumentos de operacionalização do conhecimento (as técnicas) e a criatividade do pesquisador (sua experiência, sua capacidade pessoal e sua sensibilidade)".

Para Fachin (2006, p. 29), "todo trabalho científico deve ser baseado em procedimentos metodológicos, os quais conduzem a um modo pelo qual se realiza uma operação denominada conhecer, outra agir e outra fazer." Pode ser também solicitada, pela falta ou pela desordem de informações que possam ser relacionadas ou requeridas ao problema (GIL, 2010).

Esta pesquisa caracteriza-se como quantitativa, pois "é aquela em que o investigador usa primariamente alegações pós-positivas para desenvolvimento de conhecimento." (CRESWELL, 2007, p. 35). De acordo com Lakatos e Marconi (2003, p. 187) a pesquisa quantitativa "consiste em investigações de pesquisa empírica cuja principal finalidade é o delineamento ou análise das características de fatos ou fenômenos, a avaliação de programas, ou o isolamento de variáveis principais ou chave". Deste modo, foi realizado um estudo de caso em uma Maderireira no munícipio de Guarapuava-PR, com base na análise documental das faturas de energia elétrica, foi possível estabelecer o padrão de gastos em quiilowatts por 
hora $(\mathrm{kw} / \mathrm{h})$ e o valor médio em reais.

Pelo viés dos objetivos da pesquisa, o presente artigo estabelece como pesquisa exploratória, já que uma maior familiaridade com o problema torna-o mais claro ou acessível (GIL, 2010) pelo fato de ter ocorrido em uma madeireira por um determinado período. Também se caracteriza como pesquisa descritiva, já que sua elaboração tem a finalidade de identificar algumas relações entre as variáveis (GIL, 2010). Tal pesquisa teve início em 2019 por meio do diagnóstico realizado in-loco em todas as áreas da empresa. Considerando os levantamentos documentais analisados, bem como os achados na pesquisa exploratória, realizou-se a comparação das variáveis entre os gastos de energia da rede elétrica com os valores gastos de energia no sistema fotovoltaico por meio da estatística descritiva, possibilitando assim a análise de viabilidade do sistema fotovoltaico e os cálculos de retorno do investimento e tempo de retorno.

E ainda foram utilizados dos procedimentos técnicos de pesquisa bibliográfica, elaborada a partir de material já publicado, a fim de comprovar os achados da pesquisa. Visto que, o artigo irá expor a viabilidade financeira ao adquirir o sistema de energia fotovoltaica, a fim de gerar lucro para a indústria madeireira.

\section{Apresentação e Análise dos Resultados}

Com base no diagnóstico realizado no ano de 2019, foi observado de um modo geral que a indústria madeireira tem um alto consumo de energia elétrica onde acaba custando um valor alto a ser pago para concessionárias. De acordo com a análise realizada na indústria madeireira, o gasto médio de $\mathrm{R} \$ 17.000,000$ com energia elétrica por mês. A instalação das placas fotovoltaicas, exige um investimento de aproximadamente $\mathrm{R} \$ 111.500,00$, conforme o item 2 do presente trabalho a instalação das placas acaba se pagando pela economia de energia que o sistema de energia solar oferece. O custo da instalação das placas fotovoltaicas foi realizado com base em alguns orçamentos realizados por empresas especializadas em energia fotovoltaica da cidade de Guarapuava-Pr.

Como o alto consumo de energia elétrica é o que mais prejudica financeiramente o setor madeireiro, o gráfico 1 apresenta os valores dos 3 primeiros meses de 2020 gastos com energia elétrica. 
Gráfico 1 - Consumo de energia elétrica dos meses de Janeiro, Fevereiro e Março de 2020.

\section{Valor Mensal de Energia Elétrica}

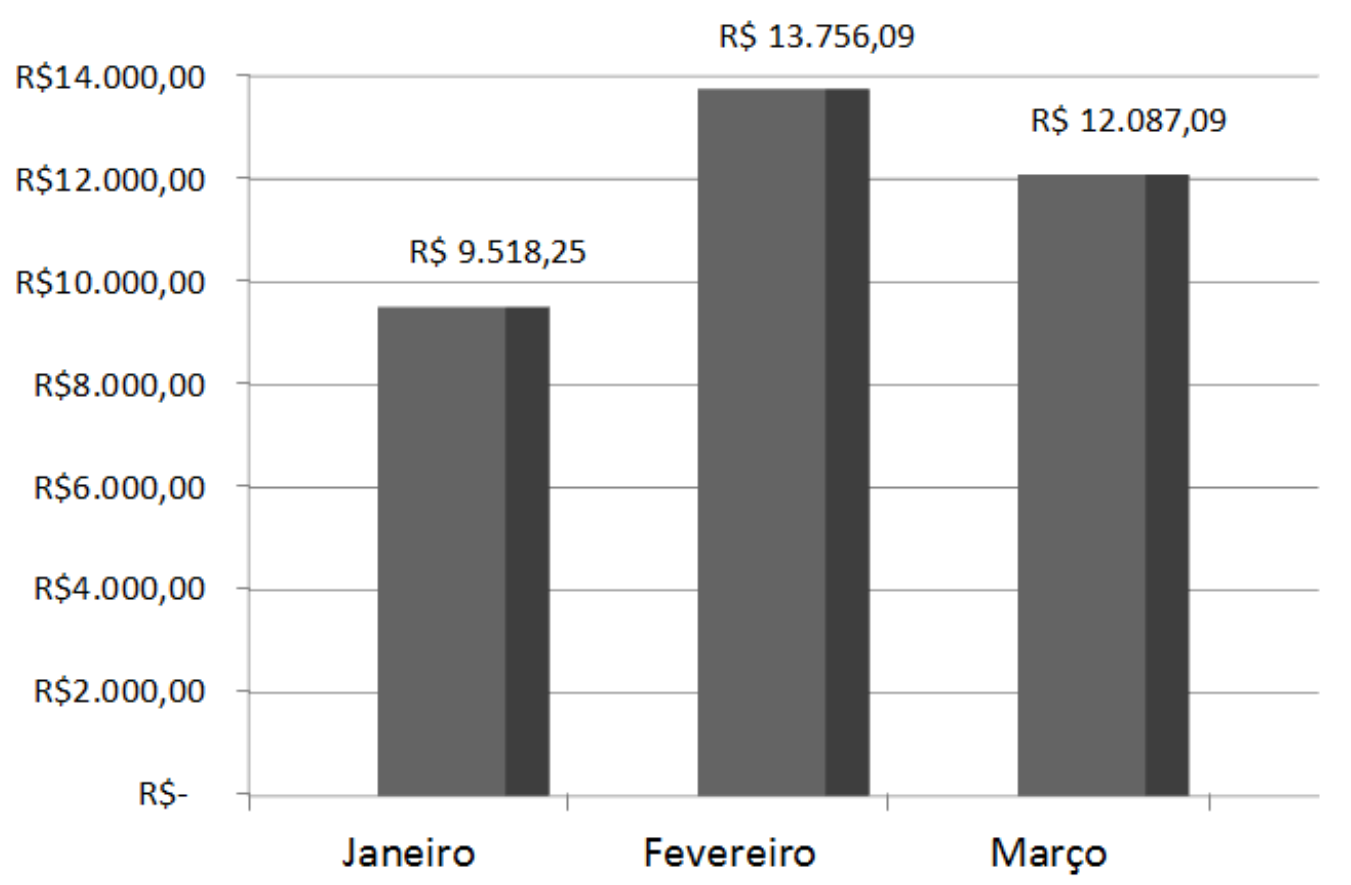

Fonte: Os Autores (2020)

No gráfico 1 observa-se que o consumo de energia elétrica é elevado por conta da exigência que o maquinário requer, a mesmo ilustra um consumo de energia elétrica dos primeiros 3 meses do ano de 2020 .

\subsection{Análise Descritiva dos Dados}

Com a instalação das placas fotovoltaicas, a indústria madeireira pode ter uma redução no custo de energia elétrica para concessionárias e logo beneficia o meio ambiente por ser um método de geração de energia limpo e renovável. A seguir segue o gráfico de consumo base em Kwh realizado por uma madeireira dentro de 12 meses. 
Gráfico 2 - Consumo de energia elétrica em Kwh

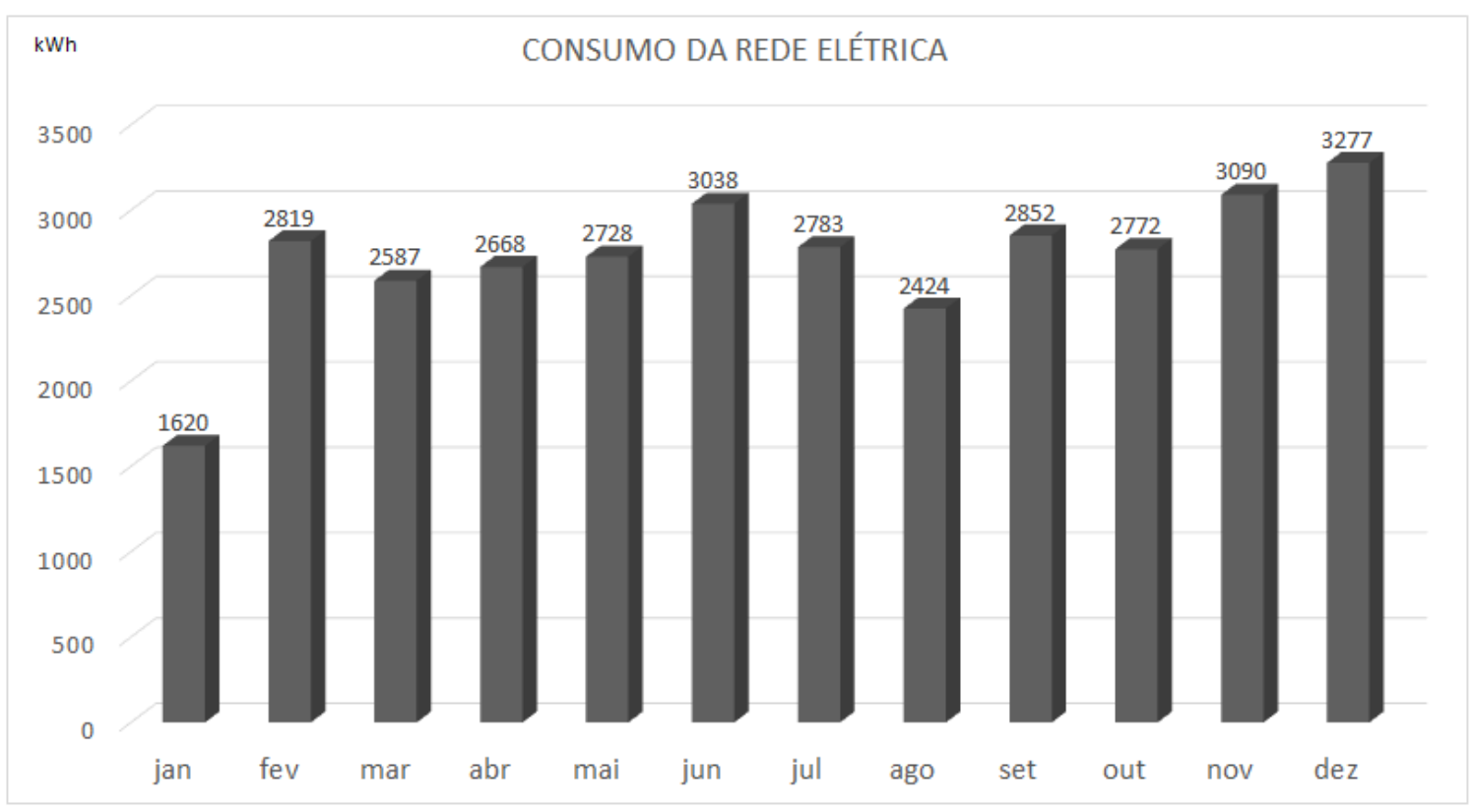

Fonte: Os Autores (2020)

De acordo com o gráfico 2 vê-se um alto consumo de energia, as madeireiras contam com máquinas potentes que demandam uma alta quantia de energia.

No gráfico 3 é exposto a quantidade de energia em Kwh fornecido pelo sistema fotovoltaico, baseando-se em um orçamento de uma empresa especializada em placas de energia solar o ideal seria a instalação em torno de 55 módulos fotovoltaicos de 410W.

Gráfico 3 - Energia fornecida pelo sistema fotovoltaico.

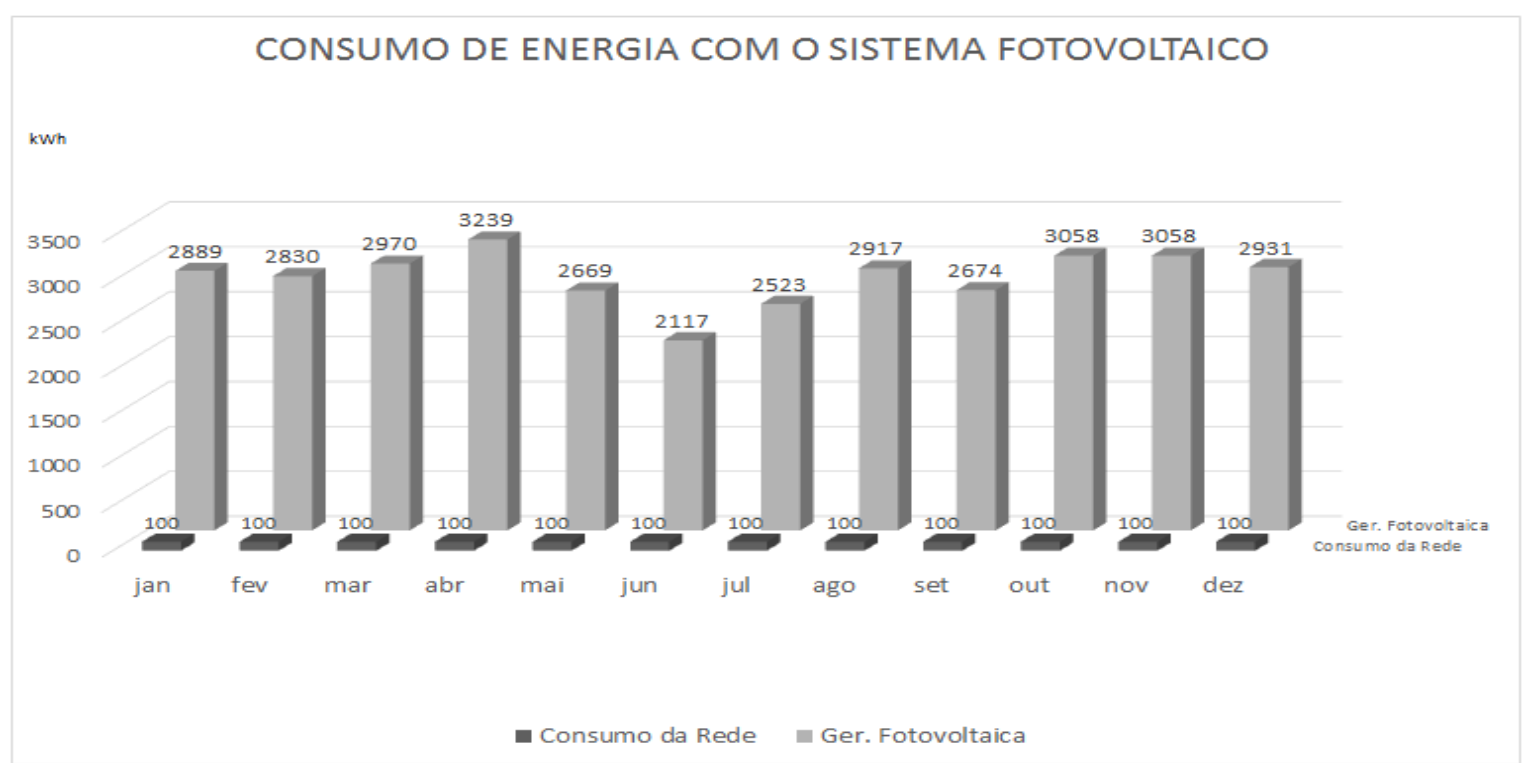

Fonte: Os autores (2020)

No gráfico 3, observa-se nas barras da cor cinza a quantidade de energia em Kwh 
fornecida pelas placas fotovoltaicas, logo as barras menores em tom mais escuro é o consumo de energia elétrica da rede das concessionárias. Caso a energia gerada pelo sistema de energia solar venha a sobrar, o mesmo fica como um crédito na fatura da concessionária para o próximo mês, trazendo esse lucro para a empresa.

A seguir será apresentada uma análise financeira dos próximos 25 anos com a utilização do sistema fotovoltaico.

Tabela 2 - Análise Financeira dos próximos 25 anos

\begin{tabular}{|c|c|c|c|c|c|c|c|}
\hline Ano & $\begin{array}{l}\text { Rendimento } \\
\text { dos painéis }\end{array}$ & $\begin{array}{c}\text { Geração anual de } \\
\text { energia (Kwh/ano) } \\
\text { considerando perda } \\
\text { do rendimento dos } \\
\text { painéis }\end{array}$ & $\begin{array}{c}\text { Geração } \\
\text { acumulada } \\
\text { de energia } \\
\text { (Kwh) }\end{array}$ & $\begin{array}{c}\% \text { de } \\
\text { reajuste } \\
\text { médio anual } \\
\text { de energia } \\
\text { aprox. }\end{array}$ & $\begin{array}{c}\text { Economia } \\
\text { Gerada/Ano } \\
\text { - R\$ - (BxE) }\end{array}$ & $\begin{array}{l}\text { Retorno do } \\
\text { Investimento } \\
\text { (R\$) }\end{array}$ & $\begin{array}{c}\text { Economia } \\
\text { Acumulada } \\
\text { (R\$) }\end{array}$ \\
\hline 10 & $99.30 \%$ & 32.887 & 32.887 & $10 \%$ & $27.493,67$ & $-84.013,55$ & $27.493,67$ \\
\hline $2 \%$ & $98.60 \%$ & 32.657 & 65.544 & $10 \%$ & $30.031,34$ & $-53.982,21$ & $57.525,01$ \\
\hline $3 \circ$ & $97.91 \%$ & 32.428 & 97.972 & $10 \%$ & $32.803,23$ & $-21.178,98$ & $90.328,24$ \\
\hline $4^{\circ}$ & $97.23 \%$ & 32.201 & 130.174 & $10 \%$ & $35.830,97$ & $14.651,99$ & $126.159,21$ \\
\hline $5 \circ$ & $96.55 \%$ & 31.976 & 162.150 & $10 \%$ & $37.138,17$ & $53.790,15$ & $165.297,37$ \\
\hline $6 \div$ & $95.87 \%$ & 31.752 & 193.902 & $10 \%$ & $42.750,62$ & $96.540,77$ & $208.047,99$ \\
\hline $7 \circ$ & $95.20 \%$ & 31.530 & 225.432 & $10 \%$ & $46.696,50$ & $143.237,27$ & $254.744,49$ \\
\hline 8 & $94.54 \%$ & 31.309 & 256.741 & $10 \%$ & $51.006,59$ & $194.243,86$ & $305.751,08$ \\
\hline $9 \circ$ & $93.87 \%$ & 31.090 & 287.831 & $10 \%$ & $55.714,50$ & $249.958,36$ & $361.465,58$ \\
\hline $10^{\circ}$ & $93.22 \%$ & 30.872 & 318.703 & $10 \%$ & $60.856,94$ & $310.815,30$ & $422.322,52$ \\
\hline $11 \div$ & $92.56 \%$ & 30.656 & 349.359 & $10 \%$ & $66.474,04$ & $377.289,34$ & $488.796,56$ \\
\hline $12 \%$ & $91.92 \%$ & 30.442 & 379.801 & $10 \%$ & $72.609,59$ & $449.898,94$ & $561.406,16$ \\
\hline $13^{\circ}$ & $91.27 \%$ & 30.229 & 410.030 & $10 \%$ & $79.311,46$ & $529.210,40$ & $640.717,62$ \\
\hline $14^{\circ}$ & $90.63 \%$ & 30.017 & 440.047 & $10 \%$ & $86.631,91$ & $615.842,31$ & $727.349,53$ \\
\hline $15 \%$ & $90.00 \%$ & 29.807 & 469.853 & $10 \%$ & $94.628,03$ & $710.470,34$ & $821.977,56$ \\
\hline $16^{\circ}$ & $89.37 \%$ & 29.598 & 499.452 & $10 \%$ & $103.362,20$ & $813.832,54$ & $925.339,76$ \\
\hline $17^{\circ}$ & $88.74 \%$ & 29.391 & 528.843 & $10 \%$ & $112.902,53$ & $926.735,07$ & $1.038 .242,29$ \\
\hline $18^{\circ}$ & $88.12 \%$ & 29.185 & 558.028 & $10 \%$ & $123.323,44$ & $1.050 .058,51$ & $1.161 .565,73$ \\
\hline $19 \circ$ & $87.51 \%$ & 28.981 & 587.099 & $10 \%$ & $134.706,19$ & $1.184 .764,69$ & $1.296 .271,91$ \\
\hline $20^{\circ}$ & $86.89 \%$ & 28.778 & 615.787 & $10 \%$ & $147.139,57$ & $1.331 .904,26$ & $1.443 .411,48$ \\
\hline $21 \%$ & $86.28 \%$ & 28.577 & 644.364 & $10 \%$ & $160.720,55$ & $1.492 .624,82$ & $1.604 .132,04$ \\
\hline $22 \%$ & $85.68 \%$ & 28.377 & 672.740 & $10 \%$ & $175.555,06$ & $1.668 .179,87$ & $1.779 .687,09$ \\
\hline $23^{\circ}$ & $85.08 \%$ & 28.178 & 700.918 & $10 \%$ & $191.758,79$ & $1.859 .938,66$ & $1.971 .445,88$ \\
\hline $24^{\circ}$ & $84.49 \%$ & 27.981 & 728.899 & $10 \%$ & $209.458,13$ & $2.069 .396,79$ & $2.180 .904,01$ \\
\hline $25 \circ$ & $83.89 \%$ & 27.785 & 756.684 & $10 \%$ & $228.791,11$ & $2.298 .187,90$ & $2.409 .695,12$ \\
\hline
\end{tabular}

Fonte: Os Autores (2020)

A tabela 2 expõe uma análise financeira para os próximos 25 anos para uma madeireira, temse como base de cálculo as seguintes informações:

- Custo médio do kWh: R\$ 0,76;

- Geração média mensal do sistema: 2.760 kWh;

- Aderiu à isenção do ICMS? Sim;

- ICMS: Isento;

- PIS: Isento;

- COFINS: Isento;

- Economia gerada pelo sistema fotovoltaico: $\mathrm{R} \$ 0,76$; 
- Investimento: R\$ 111.507,22;

A seguir será exibido outro gráfico comparativo com a média de gasto em reais com energia elétrica fornecida somente pela concessionária sem o sistema fotovoltaico e outro valor em R\$ de gasto com energia já com o sistema de energia solar instalado.

Gráfico 4 - Comparação de valores sem e com o sistema fotovoltaico.

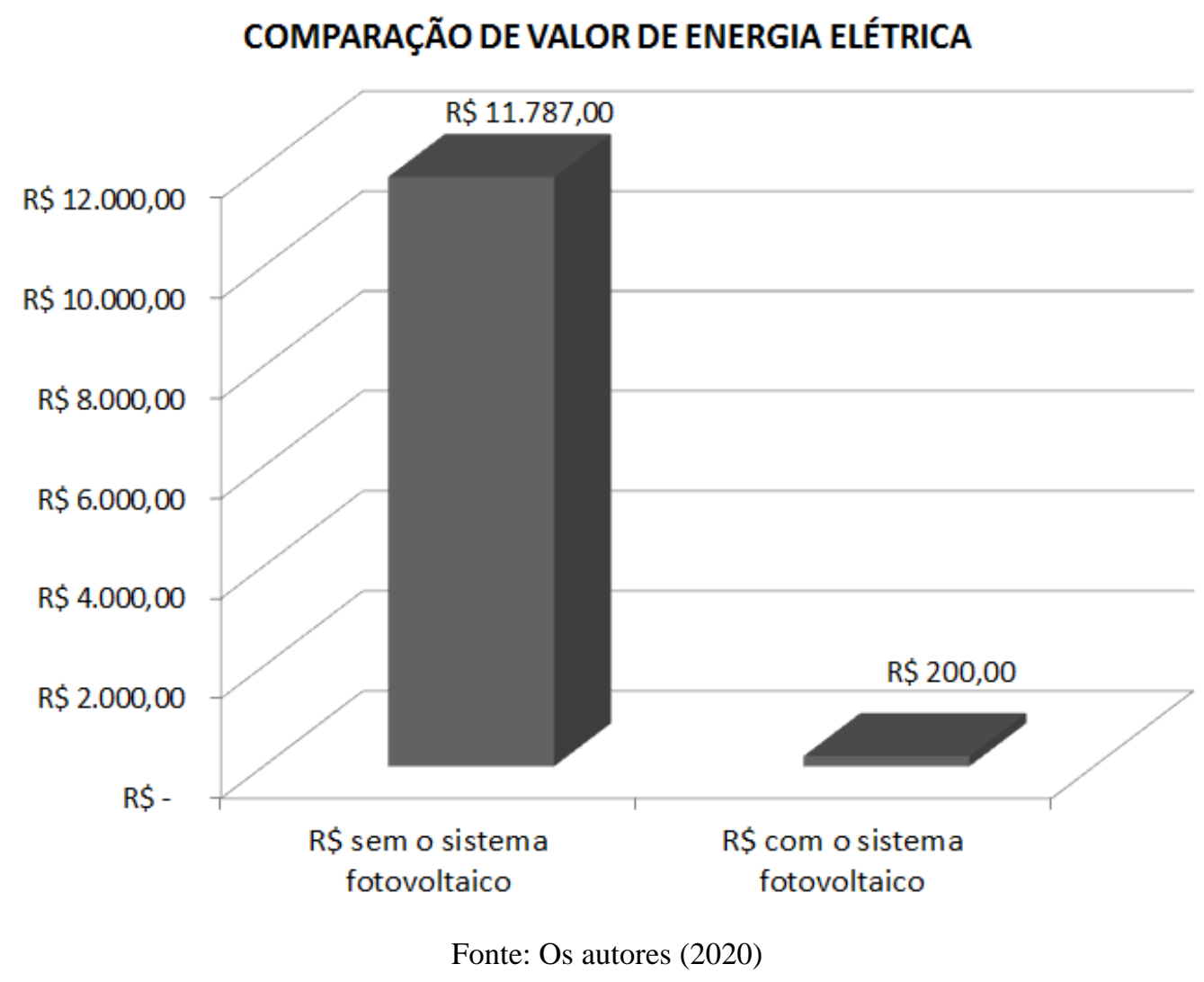

De acordo com o gráfico 4, foi exposto um comparativo de gastos, pode-se notar a diferença em $\mathrm{R} \$$ que a madeireira teria que pagar caso tenha e não tenha o sistema fotovoltaico instalado.

A partir das informações apresentadas conclui-se que a aquisição do sistema fotovoltaico vem a ser benéfico para a indústria madeireira, como observa-se na figura 2 nos próximos 25 anos a empresa pode vir a ter um lucro de aproximadamente de $\mathrm{R} \$ 2.298 .187,90$ e logo terá o retorno do investimento em 3 anos e 7 meses. Ressaltando que as informações adquiridas no presente trabalho tem como base o auxílio de uma empresa especializada em Energia Solar Fotovoltaica e logo foi realizado um orçamento para tal análise. 


\section{Conclusões}

Diante do objetivo apresentado, sobre a instalação de placas de energia solar em madeireiras, atualmente é uma realidade no setor da indústria madeireira, porém nem todas as madeireiras dispõem do sistema de energia solar. O objetivo do presente trabalho é expor os benefícios que esse sistema traz e todas as suas condições de aquisição. Com o cenário atual a maior dificuldade em adquiri-lo é o custo de investimento que se deve dispor, o retorno se dá em longo prazo e isso é o que gera dúvidas na aquisição. $\mathrm{O}$ objetivo proposto não foi atingido até momento devido a crise econômica que se encontra no Brasil.

Tendo em vista que o método de geração de energia solar através do sistema fotovoltaico na indústria madeireira seja pouco explorado e contém poucos estudos sobre o assunto, esta é considerada também como a maior dificuldade para a conclusão do presente trabalho.

O presente trabalho sugere estudos mais aprofundados com empresas que fornecem os painéis fotovoltaicos, essas empresas contêm informações técnicas precisas para cada tipo de estabelecimento, analisando precisamente a necessidade individual de cada negócio. Este estudo é aplicável apenas em empresas do setor da indústria madeireira devido ao grande consumo de energia elétrica que as mesmas utilizam por possuírem máquinas de grande porte, porém o sistema de energia solar é aplicável para outros setores da economia, inclusive para residências, mas o mesmo deve ser orçado e avaliado individualmente pela empresa competente.

Assim, percebe-se que a energia fotovoltaica apesar de ter um alto custo é uma solução vantajosa para as indústrias madeireiras em longo prazo, pois possibilita a economia em financeira e favorece o meio ambiente gerando energia limpa.

\section{REFERÊNCIAS}

ANEEL. Geração Distribuída. Disponível em: https://www2.aneel.gov.br/area.cfm?idArea=757\&idPerfil=2. Acesso em: 14 mar. 2020.

CRESWELL, John W. Projeto de Pesquisa: métodos qualitativo, quantitativo e misto. 2. ed. - Porto Alegre: Artmed, 2007.

DESLANDES, Suely Ferreira. GOMES, Romeu, MINAYO, Maria Cecilia Pesquisa Social: teoria, método e criatividade. 28. ed.- Petropolis, RJ: Vozes, 2009.

FACHIN, O. Fundamentos de Metodologia. 5. ed. São Paulo: Saraiva, 2006. 
FRASÃO, Lucas; BARRA, Mário; MENICONI, Tadeu. Entenda como a geração de energia elétrica afeta o meio ambiente: cada tecnologia tem um impacto diferente sobre a natureza. custos e viabilidade também devem ser levados em conta na comparação.. Cada tecnologia tem um impacto diferente sobre a natureza. Custos e viabilidade também devem ser levados em conta na comparação.. 2011. Disponível em: http://g1.globo.com/ciencia-esaude/noticia/2011/03/entenda-como-geracao-de-energia-eletrica-afeta-o-meio-

ambiente.html. Acesso em: 01 maio 2020.

GIL, Antonio Carlos, 1946 - Como elaborar projetos de pesquisa. 5. ed. - São Paulo: Atlas, 2010.

LAKATOS, Eva Maria. MARCONI, Mariana de Andrade. Fundamentos de metodologia científica 5. ed. - São Paulo : Atlas 2003.

MÜLLER, Natália. Energia solar em indústrias e fábricas. Disponível em: https://www.solarvoltenergia.com.br/blog/energia-solar-em-industrias-e-fabricas/. Acesso em: 17 mar. 2020.

QUANTUM. Madeireira na grande Florianópolis é exemplo de economia com a utilização de energia solar. 2019. Disponível em: https://www.quantumengenharia.net.br/madeireira-economia-com-energia-solar/. Acesso em: 10 mar. 2020.

SOLARPRIME. 7 vantagens de usar energia solar em indústrias e fábricas. 2019. Disponível em: https://blog.solarprime.com.br/vantagens-energia-solar-em-industrias-efabricas/. Acesso em: 17 mar. 2020.

SOUSA, Rafaela. Energia Solar. Disponível em: https://brasilescola.uol.com.br/geografia/energia-solar.htm. Acesso em: 09 mar. 2020.

SUNERGIA. Energia solar fotovoltaica: sustentabilidade e economia. 2018. Disponível em: https://sunergia.com.br/blog/energia-solar-fotovoltaica-sustentabilidade-e-economia-2/.

Acesso em: 29 mar. 2020.

UOL. Eletricidade é o setor campeão na emissão dos gases de efeito estufa. 2015. Disponível em: https://noticias.uol.com.br/meio-ambiente/ultimasnoticias/redacao/2015/12/07/eletricidade-e-o-setor-campeao-na-emissao-dos-gases-do-efeitoestufa.htm. Acesso em: 01 abr. 2020.

VILLALVA, Marcelo Gradella. Energia Solar Fotovoltaica: conceitos e aplicações. 2020. Conceitos e Aplicações. Disponível em: https://books.google.com.br/books?hl=ptBR\&lr=\&id=M4diDwAAQBAJ\&oi=fnd \&pg=PP3\&dq=energia + solar+fotovoltaica\&ots=z3j ad0g4P\&sig=_7MPct19pMOfwM4QH5yuRzGgv0Y\#v=onepage\&q\&f=true. Acesso em: 05 mar. 2020. 